\title{
O INTELECTUAL UNIVERSITÁRIO E SEU TRABALHO EM TEMPOS DE "PESQUISA ADMINISTRADA"
}

Lucídio Bianchetti*

Antonio Alvaro Soares Zuin**

\begin{abstract}
"Eso provocó que, para salvar su puesto e su sueldo, los profesores comenzaran a trabajar más en el marketing de su currículo que en sus clases y en suas investigaciones. Se obstaculizó así la vida acadêmica com una maraña de demandas imposibles de cumplir, pues las normativas cambiaban a diario". (FERNÁNDEZ LIRIA; SERRANO GARCÍA, 2009, p. 14)
\end{abstract}

RESUMO: T. Adorno, ao chegar aos EUA na década de 1940, surpreende-se com o novo ethos da pesquisa com o qual se defronta e estranha os mecanismos de controle que pesavam sobre a academia e os pesquisadores. Nos EUA, esses mecanismos convergiram para uma síntese contida na fórmula "publish orperish", processo que acabou instaurando-se no Brasil a partir de meados da década de 1990. É sobre esse processo, ao qual foram submetidos os intelectuais na universidade e as consequências para a produção e veiculação do conhecimento, que dedicamos nossa atenção neste texto. Por meio deste artigo, objetivamos investigar a forma como a produção intelectual vem desenvolvendo-se em tempos nos quais a pesquisa científica torna-se cada vez mais administrada pela lógica do fetiche da mercadoria cultural, com destaque para a análise do modo como a lógica do publique ou pereça delineia a forma da produção científica no Brasil.

Palavras-chave: Indústria Cultural; Intelectual; Produção e Veiculação do Conhecimento.

\footnotetext{
*Doutor em Educação pela Pontifícia Universidade Católica de São Paulo (PUC/SP); Professor Associado na Universidade Federal de Santa Catarina (UFSC); Bolsista de Produtividade 1C do Conselho Nacional de Desenvolvimento Científico e Tecnológico (CNPq); Coordenador do Grupo de Pesquisa "Trabalho e Conhecimento na Educação Superior" (TRACES, UFSC). E-mail: lucidio.bianchetti@pq.cnpq.br

** Doutor em Educação pela Universidade Estadual de Campinas (UNICAMP); Professor Associado da Universidade Federal de São Carlos (UFSCar); Bolsista Produtividade 1C do Conselho Nacional de Desenvolvimento Científico e Tecnológico (CNPq); Coordenador do Grupo de Pesquisa: "Teoria Crítica e Educação" da Universidade Federal de São Carlos (UFSCar). E-mail: dazu@ufscar.br
} 


\section{UNIVERSITY SCHOLARS AND THEIR WORK IN TIMES OF "ADMINISTERED RESEARCH"}

ABSTRACT: Upon arriving in the United States in the 1940s, Theodor Adorno was surprised with the new research ethos he found and perplexed by the various control mechanisms that influenced the academy and its researchers. He began to realize their implications on the quality of research process and product and the education of future researchers. In the USA, these changes converged towards a synthesis expressed by the formula "publish or perish," a process that was instilled in Brazil as from the mid-1990s, with all of the consequences that had been identified in other spaces. This article analyzes the transformations university scholars were submitted to and their consequences on knowledge production and dissemination. The article investigates how intellectual production is undertaken at a time in which scientific research has become increasingly administered under the logic of the fetish of cultural merchandise. It also analyzes how the "publish or perish" logic influences the form of scientific production in Brazil.

Keywords: Cultural Industry; Scholar; Knowledge Production and Dissemination.

\section{INTRODUÇÃo}

Nunca o tema da produção acadêmica esteve tão em voga quanto atualmente. A aceleração do tempo de realização das pesquisas, cujos resultados precisam rapidamente tornar-se públicos em periódicos de seletiva política editorial, livros e capítulos de livro e trabalhos em congressos científicos, transforma-se na condição de existência e sobrevivência do pesquisador na esfera acadêmica. As relações do mundo da vida acadêmica caracterizam-se cada vez mais pela desconfiança na exposição de dados de pesquisa que podem ser utilizados por colegas para a publicação de seus respectivos papers. Não por acaso, desenvolve-se um clima cultural propício ao surgimento de traços paranoicos, como se o colega de departamento, cuja sala está ao lado, pudesse apropriar-se de determinadas ideias e utilizá-las em proveito próprio para publicar seus textos. Ou então a paranoia objetiva-se no comportamento do colega que culpabiliza o coordenador de um programa de pós-graduação pelo seu impedimento em orientar dissertações de mestrado e teses de doutorado, justamente por não ter atingido a meta de publicações de 'produtos' acadêmicos determinada pela CAPES, como se essa fosse uma decisão de exclusiva responsabilidade do coordenador ${ }^{1}$ do Programa de pós-graduação. É desse modo que o escopo original da universidade, cujos partícipes deveriam compartilhar e universalizar a produção do conhecimento, arrefece-se diante da velocidade de reposição 
dos chamados 'produtos' científicos ${ }^{2}$. É nesse contexto que se pode observar como a lógica do delírio paranoico se nutre de outro tipo de lógica: a do fetiche das mercadorias culturais.

Muito mais importante do que a necessária maturação da ideia que gradativamente se converte numa hipótese de pesquisa a ser analisada com paciência e rigor científico, o que de fato interessa é a publicação imediata de determinados dados, num tipo de açodamento que pode ser constatado na atual propagação de produções científicas de pesquisadores que repetem ad nauseam as mesmas conclusões em seus trabalhos. Os detalhes que são exaltados por tais pesquisadores em seus respectivos textos somente iluminam o mais do mesmo, ou seja, que são particularidades diluídas em trabalhos praticamente idênticos entre si, levando Kuenzer e Moraes (2005) a fazer referência a publicações de diversas versões "requentadas" de um mesmo artigo. Em certas situações, a duplicidade de resultados, presente nas pesquisas das ciências exatas, biológicas e humanas, adquire tamanho vulto que os holofotes midiáticos são direcionados ao pesquisador que procedeu dessa forma, personalizando o problema como se fosse de sua única responsabilidade, impondo a necessidade de (re)discutir o plágio e o autoplágio em um contexto de indução ao "produtivimo acadêmico" no qual pouco tempo-espaço resta ao trabalho autônomo, condição para a originalidade (PAQUOT, 1998) ${ }^{3}$. Mas a avidez pelo número cada vez maior de produtos científicos publicados não pode ser exclusivamente identificada como uma idiossincrasia de determinado indivíduo, pois é fundamental compreender a compulsão pela publicação de produtos acadêmicos como uma característica de um espírito do tempo. O mesmo espírito do tempo que impinge o recrudescimento da quantidade em detrimento da qualidade de tais produtos. O publish or perish parece ter atingido o paroxismo.

A personalização do ato compulsivo de publicar os resultados das pesquisas o mais rapidamente possível apraz à ideologia de que tal comportamento não tem quaisquer relações com a forma hegemônica de proliferação dos bens culturais. Mas a atual mercantilização do espírito não pode ser apartada da cultura cujo processo de industrialização exige a produção e reprodução das denominadas mercadorias culturais. Talvez a expressão "bens culturais" fosse mais adequada à atual situação do que a designação "produtos culturais", mas, se ocorresse tal substituição, o teor mercadológico que deles emanaria tornar-se-ia tão evidente que não haveria 
mais a possibilidade da existência do verniz ideológico de cultura, capaz de envolvê-los em embalagens mais vistosas e brilhantes. Diante do sortilégio de tal brilho, é preciso realizar a análise crítica do modo como o trabalho intelectual é atualmente produzido como se fosse mais uma mercadoria cultural. Daí o objetivo deste artigo: investigar a forma como a produção intelectual se desenvolve em tempos nos quais a pesquisa científica torna-se cada vez mais administrada pela lógica do fetiche da mercadoria cultural. Pois, de acordo com essa lógica, arrefece-se a dimensão formativa dos produtos culturais na medida em que se tornam mercadorias, cuja magnitude do valor, determinada de acordo com o sistema de ranqueamento Qualis, materializa a forma de sua intercambialidade no mercado de bens científicos. Desse modo, torna-se necessária a investigação do modo como o imperativo "publique ou pereça” delineia os contornos da produção científica em nosso país.

\section{INDÚSTRIA CULTURAL, SEMIFORMAC̣ÃO E PESQUISA ADMINISTRADA}

Quando Theodor W. Adorno e Max Horkheimer apresentaram o conceito de indústria cultural, no livro Dialética do Esclarecimento: fragmentos filosóficos (ADORNO; HORKHEIMER, 1986), em 1944, identificaram um processo de produção da cultura que se consagrou nos chamados filmes hollywoodianos da primeira metade do século passado, mas cuja origem remonta às primeiras décadas do século XVII. O senso crítico desses pensadores frankfurtianos foi capaz de perceber as nuances ideológicas da produção cada vez mais massificada da cultura, a mesma cultura que era ofertada ao consumidor como se fosse algo exclusivo e, dessa forma, atendesse a demanda específica de um determinado indivíduo. Assim, o produto cultural que era massificado e padronizado até a sua raiz vicejava como se fosse o refúgio do imediatismo e da vida. Porém, ele era mediado pela lógica do fetiche da mercadoria antes mesmo de sua existência concreta, ou seja, já no processo de sua concepção.

Não é correto afirmar que os indivíduos consumiriam tais produtos da indústria cultural passiva e cordeirescamente, como se não houvesse quaisquer possibilidades de resistir ao sortilégio do consumo das mercadorias denominadas culturais. Mas a verdade de que não é possível estipular uma mera relação de causa e efeito entre o consumo desses bens culturais e 
comportamentos de estultice e dessensibilização não pode servir como uma defesa, como uma justificativa para o consumo desenfreado dessas mesmas mercadorias, por meio de propagandas que visam a venda da imagem de que se trata de algo que é afeito ao chamado jeito de ser, à particularidade de quem as consome.

É preciso compreender o modo como os consumidores dos produtos da indústria cultural se esforçam ativamente para manter a passividade e a resignação de que parece não haver outra forma de produção e reprodução da cultura. É por isso que, como asseveraram Adorno e Simpson, os consumidores de tais produtos se assemelham àqueles insetos que rodopiam fascinados em torno das lâmpadas coloridas, cujos brilhos dissimulam, nem que seja por um breve e fugaz momento, a opacidade da vida desses homens-insetos. Mas, "[...] para ser transformado em inseto, o homem precisa daquela energia que eventualmente poderia efetuar a sua transformação em homem [...]" (ADORNO; SIMPSON, 1986, p. 146). A dificuldade de utilizar-se tal energia para poder novamente humanizar-se corresponde ao recrudescimento da admiração dos artefatos que se digladiam para poder capturar a atenção e serem consumidos. Evidentemente, a produção e reprodução dos chamados bens culturais não se furta dessa necessidade de autopropagandear-se, o que implica investigação do início de tal processo. Para Christoph Türcke, as origens da mercantilização dos produtos simbólicos podem ser observadas já na publicação dos jornais desde o século XVII da seguinte forma:

O meio precisa ser semanalmente, depois diariamente, alimentando com matérias dignas de serem noticiadas, para que ele possa continuar a existir e, quando se torna questionável se os eventos correntes dizem respeito a todos, é necessário que se faça que se digam. Assim, a confecção de notícias recebe uma nova ênfase. Não mais representa apenas a ornamentação de acontecimentos explosivos, mas também o fazer explosivo dos acontecimentos. A lei de base da lógica da notícia conduz à sua própria inversão: "A ser comunicado, porque importante" superpõe-se a "Importante, porque comunicado". (TÜRCKE, 2010, p. 17).

Os jornais científicos que noticiavam as informações de interesse geral da população, tais como a aproximação de tropas inimigas ou a danificação de reservatórios de água, ainda estavam inseridos nessa lógica do "A ser comunicado, porque importante". Já nas primeiras décadas do século XVII, essa lógica inverte-se e o que de fato importa é comunicar algo que capture 
a atenção do consumidor. É nesse sentido que o denominado valor de uso da informação se submete ao seu valor na forma da troca. Não por acaso, as notícias são identificadas como news em inglês, ou seja, doravante o que interessa é o controle da difusão das novidades que possibilitarão a uma determinada empresa jornalística destacar-se em relação à sua concorrente. De lá para cá, a avidez cada vez maior pelo controle da produção e reprodução dessas novidades, dessas news, transforma-se no principal anelo do processo de mercantilização de produtos simbólicos, sobretudo na sociedade da indústria cultural cujos alicerces se fundamentam no gelatinoso terreno dos espetáculos contínuos. Foi Debord aquele que, ao analisar as características da chamada sociedade do espetáculo, observou o modo como as imagens espetaculares se fetichizam a ponto de adquirirem vida própria. $\mathrm{Na}$ verdade, o espetáculo não pode ser distinguido como um conjunto de imagens, mas sim como relações entre pessoas mediadas por imagens (DEBORD, 1997).

O esquecimento dessa advertência de Debord, de que o espetáculo precisa ser identificado como relações humanas mediadas por imagens, recrudesce o fascínio que as imagens exercem, principalmente em tempos nos quais o desenvolvimento tecnológico da produção e reprodução imagética oferta ao consumidor a sensação de que tais imagens não apenas representam, mas sim são o real. $\mathrm{Na}$ atual sociedade, na qual a construção e elaboração de representações simbólicas arrefecem-se na medida em que a realidade é representada de forma absolutamente verossímil, nota-se a forma como se revitaliza outro conceito elaborado por Theodor W. Adorno: a chamada semiformação, definida por esse pensador frankfurtiano como a conquista do espírito pela lógica do fetiche da mercadoria.

De acordo com Adorno, a semiformação apresenta-se como o processo formativo pronto e acabado, embora esteja muito distante de sê-lo. A semiformação pode também ser definida como o correlato subjetivo da indústria cultural, especialmente quando, do contato com os seus produtos, derivam-se prejuízos consideráveis na experiência formativa. A danificação do espírito decorre do processo de solapamento da memória e, portanto, das mediações históricas que determinam as nuances identitárias dos indivíduos. Ao invés da consciência da atuação de tais mediações nos vínculos estabelecidos entre o particular e o geral, entre o indivíduo e a sociedade, o que se tem é justamente a presença de um raciocínio binário que classifica e rotula pessoas e situações em polos opostos, tais como amigos e inimigos, 
estar por dentro ou por fora. Não é fortuito o comportamento do indivíduo semiformado que se jacta de conhecer de tudo um pouco, ou então de não ter tempo de aprofundar-se no estudo de um determinado assunto, pois a vida é tão corrida que se torna cada vez mais difícil alcançá-la.

Com efeito, a velocidade de produção e publicação das informações expressa, no campo da produção simbólica, o ritmo frenético de produção e consumo das mercadorias. O fato dos livros, capítulos de livros, artigos científicos e trabalhos apresentados e disponibilizados em anais de congresso serem designados como produtos já ilustra a conotação mercadológica imanente a todos eles. É interessante observar como a seguinte constatação de Adorno pode ser empregada como chave de leitura da atual situação do intelectual inserido num programa de pós-graduação: "A própria ocupação com coisas do espírito tornou-se entrementes algo 'prático' um empreendimento com rigorosa divisão de trabalho4, com ramos e restrições à entrada." (ADORNO, 2008, p. 17).

A intensidade da relação entre espírito e mundo fenomênico pode ser observada desde os primórdios do pensamento filosófico, assim como as origens da divisão entre trabalho manual e intelectual são difíceis de serem precisamente delineadas no tempo da história das relações de produção. Por meio da leitura dessa mesma história é possível notar como o trabalho manual, bem como as coisas do mundo fenomênico, foi desvalorizado diante da aparente supremacia do trabalho intelectual e da esfera do espírito. Contudo, na sociedade cujas relações de produção tendem a transformar tudo e todos em mercadorias vendáveis, nem mesmo a esfera do espírito consegue se safar. O próprio Adorno, no texto: "Experiências científicas nos Estados Unidos", relata o choque que teve quando adentrou no solo americano na condição de fugitivo do nazismo durante a segunda guerra mundial.

De fato, pode-se imaginar o choque cultural de um intelectual europeu educado com o objetivo de interpretar fenômenos e não de se identificar por meio de determinados sistemas classificatórios. Essa diferença cultural, que tanto espantou Adorno, foi exposta principalmente quanto à questão do método:

[...] inquietava-me um problema metodológico fundamental: a palavra método, entendida em seu sentido europeu de crítica do conhecimento mais que no norte-americano, segundo o qual "methodology" significa, mais ou menos, técnicas práticas de investigação [...] (ADORNO, 1995, p. 143). 
No mesmo texto, faz referência à chamada investigação administrada, cuja expressão pode também ser traduzida como pesquisa administrada, da seguinte maneira:

Pela primeira vez via diante de mim administrative research (investigação administrada): hoje já não recordo se foi Lazarsfeld quem cunhou esse conceito, ou se fui eu, em meu assombro diante de um tipo de ciência diretamente orientada para o prático, coisa para mim insólita [...] (ADORNO, 1995, p. 142).

Essa diferença epistemológica sobre o significado do conceito de método de pesquisa é interessante de ser demarcada, sobretudo porque a compreensão do método como crítica do conhecimento não implicava recusa do emprego de técnicas práticas de investigação, haja vista o fato de que o próprio Adorno, ao participar com vários intelectuais da organização da pesquisa empírica sobre a formação da personalidade autoritária nos Estados Unidos, utilizou dados obtidos por meio de questionários e testes psicológicos projetivos. Mas a ausência de incompatibilidade entre a crítica do conhecimento e técnicas práticas de investigação, quando pensadas como método, não deve suscitar a resistência à reflexão de que pesquisa administrada pode muito bem significar produtivismo acadêmico (BIANCHETTI; MACHADO, 2009). No texto “Tabus a respeito do professor”, Adorno já havia observado em meados da década de 1960, o modo como o professor universitário estadunidense e, num ritmo um pouco mais lento, o professor universitário alemão estavam, com as publicações de seus produtos, se transformando numa espécie de "[...] vendedores de conhecimento[...]" (ADORNO, 1971, p. 76). Mas talvez até mesmo o pensador frankfurtiano se assustasse diante da atual velocidade alucinante de produção de mercadorias simbólicas em tempos do Qualis-Capes.

\section{A APORTAGEM DO PUBLISH OR PERISH NO BRASIL}

Quando, em meados do século passado, no Brasil, a pesquisa e a Pós-Graduação institucionalizadas davam seus primeiros e tímidos passos, nos EUA as evidências daquilo que viria a ser a direção da produção e da veiculação do conhecimento nesse país e daqueles que gravitariam, na condição de satélites, em torno do Império, há muito havia sido dada e assumida. A divisa "publish orperish" foi a mais poderosa síntese da ameaça, 
tal como espada de Démocles, pairando sobre a cabeça de cada pesquisador individualmente, sem deixar de acometer igualmente os coletivos nas universidades.

Passadas poucas décadas ${ }^{5}$ e as críticas a essa postura hegemônica, bem como as decorrências do predomínio ou da busca por todos os meios de evitar o "perecer", apareciam nos EUA em obras que procuravam sintetizar o mal-estar, o enfado, a apatia, as resistências e as adesões, traduzindo-se em estratégias de sobrevivência. Exemplares neste sentido são as obras de: a) David Sternberg, How to Complete and Survive a Doctoral Dissertation, publicada em 1981, focalizando os desafios e as peculiaridades da sobrevivência à elaboração da dissertação/tese; b) Russel Jacoby, Os últimos intelectuais. A cultura Americana na Era da Academia, concluída em 1987 e publicada no Brasil em 1990, que aborda a questão do ponto de vista mais da academia; c) deste mesmo autor, O fim da utopia. Política e cultura na era da apatia, escrito em 1999 e publicado no Brasil em 2001, obra que, sem perder de vista a questão dos intelectuais acadêmicos, amplia seu raio de análise e crítica a outros personagens e esferas sociais.

Jacoby (1990) anuncia que seu ponto de partida é a questão: “Onde estão os intelectuais mais jovens?”' (p. 9). Sua tese é a de que os 'intelectuais', que fazem dos meios de comunicação, redundantemente, seus meios de comunicação com o grande público, ocuparam o espaço que era preenchido pelos intelectuais públicos e que com isto a cultura pública sofreu efeitos danosos. Porém, isto ocorreu muito mais em função de uma retirada dos intelectuais jovens para um outro espaço, do que propriamente por terem sido forçados a tomar essa atitude. Conforme o autor, "[...] os intelectuais mais jovens, cujas vidas se desenvolveram quase inteiramente nos campi, se dirigem aos colegas de profissão, mas são inacessíveis e desconhecidos para as outras pessoas [...]" (p. 10). A isto o autor caracteriza como uma "ausência". $\mathrm{E}$, ao referir-se ao locus de formação e de atuação desses intelectuais, lança mão de uma metáfora que aparece na abertura do Manifesto do Partido Comunista de Marx e Engels, embora com outras palavras e referindo-se a um contexto menos amplo:

Um espectro ronda as universidades americanas ou, pelo menos, seu corpo docente: o enfado. Uma geração de professores entrou nas universidades em meados e no final da década de 1960, quando os campi explodiam de tanta energia; hoje esses professores estão visivelmente entediados, se não desmoralizados [...] (JACOBY, 1990, p. 13). 
E, na sequência, refina o seu foco, apontando para a ambiência universitária, fazendo uma análise que soa à denúncia:

Os intelectuais mais jovens não necessitam ou desejam um público mais amplo; quase todos são apenas professores. Os campi são seus lares. Os colegas, sua audiência; as monografias e os periódicos especializados, seu meio de comunicação. Ao contrário dos intelectuais do passado, eles se situam dentro de especialidades e disciplinas - por uma boa razão. Seus empregos, carreiras e salários dependem da avaliação de especialistas, e esta dependência afeta as questões levantadas e a linguagem empregada [...] (JACOBY, 1990, p. 19).

Avançando em sua análise, coloca em relevo o que passa a acontecer com o predomínio desta postura entrópica, com esse voltar-se para dentro da universidade e dirigir-se apenas aos pares, utilizado os meios de veiculação aos quais somente os colegas têm acesso:

Os acadêmicos escrevem para publicações especializadas que, diferentemente dos pequenos periódicos, criam sociedades insulares [...] os professores compartilham um jargão e uma disciplina. Reunindo-se em conferências anuais para trocar informações, eles constituem seu próprio universo. Um 'famoso' sociólogo ou historiador de arte é famoso para outros sociólogos ou para outros historiadores de arte, ninguém mais. À medida que se tornavam acadêmicos, os intelectuais não tinham necessidade de escrever de modo compreensível a um público leigo; não o fizeram, e acabaram perdendo a capacidade de fazê-lo (...). Os intelectuais mais jovens estão ocupados e preocupados com as exigências das carreiras universitárias [...] (JACOBY, 1990, p. 20).

Uma das decorrências dessa postura ou dessa metamorfose na direção do acadêmico, do (intra)institucional, como uma espécie de alfa e ômega da práxis dos envolvidos com a pós-graduação, é o fato de que "[...] os intelectuais mais jovens, em boa parte, passaram a encontrar na ciência, na expressão artística e na vida acadêmica suas formas de expressão, abandonando os valores que moviam suas paixões pela política." (NEVES et al., 2010, p. 98).

$\mathrm{Na}$ segunda obra que referenciamos, Jacoby (2001) aborda diretamente a questão do intelectual institucionalizado e as consequências do/no trabalho para responder a demandas, gerando uma metamorfose cuja expressão mais visível é a transformação da pesquisa - processo e produto - em valor de troca ${ }^{7}$. Essa metamorfose explícita do processo de 
pesquisa e de seus resultados em valor de troca pode ser identificada como consequência daquilo que Adorno observou em relação à profissão de ensinar, sobretudo nos EUA: "[...] o fato de que os professores, em suas respectivas especializações, haviam se transformado em verdadeiros vendedores de conhecimentos [...]" (ADORNO, 1971, p. 76). Jacoby (2001), por sua vez, detecta nos campi uma crescente apatia, uma descrença em qualquer aposta utópica, uma vez que se gerou uma convergência de que nada vale a pena, que não há alternativas, sobressaindo-se um desencanto em relação ao porvir. Ironicamente, afirma ser esta a "[...] sabedoria do nosso tempo, uma era de exaustão e recuo ${ }^{8}$ políticos [...]” (JACOBY, 2001, p. 12), manifestando sua preocupação com o colapso dos horizontes, com o recuo ou queda das ambições intelectuais, com o desânimo e com a dissimulação intelectual.

Porém, diferentemente da primeira obra, é como se nesta o autor focalizasse a falta de intelectuais ou o desvio dos rumos das suas preocupações e ações, alguns anos após a geração dos jovens intelectuais da década de 1960 voltarem-se para dentro dos campi, para o interior dos departamentos e preocuparem-se em cuidar do seu currículo, das suas publicações endereçadas à ambiência acadêmica, zelando pelos seus salários e relacionando-se vicariamente com sua instituição e seu reduzido circuito de colegas $^{9}$, perdendo a ousadia, a autonomia e passando a repetir-se nas suas falas e publicações.

É nesta perspectiva que, “[...] ao longo do século XX, os intelectuais vêm migrando para instituições, tornando-se especialistas e professores [...]” (JACOBY, 2001, p. 139). E, na medida que se institucionalizam, submetendo-se às burocracias, a sua vida intelectual é absorvida e as fragmentações entre campos das ciências e intracampos e instâncias administrativas ampliam-se. E, contrariamente a este efeito,

[...] a visão e os textos dos intelectuais contraem-se; o pensamento e a prosa tornam-se tortuosos e obscuros. Em nome do progresso, os intelectuais recuam para caminhos mais estreitos e conceitos mais acanhados, passando a desprezar a própria lucidez, prima das luzes e do Iluminismo. (JACOBY, 2001, p. 141-2).

No que diz respeito ao Brasil, há uma série de iniciativas, desde a criação e expansão do Sistema CAPES, que foram implementadas a partir de influências advindas principalmente dos EUA, seja pelos financiamentos indutores das Fundações, seja pela vinda de professores de universidades 
americanas e de assessores governamentais para atuarem no Brasil ${ }^{10}$, seja pela ida de estudantes e professores brasileiros para fazerem ou complementarem sua formação nas universidades desse país. Destacadamente a atuação de Rudolph Atcon, a implementação do Acordo MEC-USAID, da Reforma Universitária de 1968, da organização dos Planos Nacionais de Pós-graduação, entre outros, são fatores que vão direcionando a organização e o funcionamento da Pós-Graduação na perspectiva de constituir-se à imagem e semelhança do sistema norte-americano, com algumas decorrências similares como apontamos em páginas anteriores.

$\mathrm{Na}$ busca de universalizar o modo americano de vida de fazer e consumir ciência e cultura etc., enfim, de impor sua hegemonia, no decorrer dos anos de 1950 e 1960,

[...] o governo estadunidense investiu num audacioso projeto "secreto" de propaganda na Europa Ocidental, executado pela CIA. Dentre suas realizações, teve destaque o Congresso pela Liberdade Cultural, uma poderosa iniciativa que mantinha escritórios em 35 países pelo mundo, desenvolvendo ações que empregavam pessoas responsáveis pela "publicação de revistas acadêmicas", realização de exposições artísticas, organização de conferências internacionais e de premiações importantes. O objetivo de tal investimento era a construção de "mecanismos voltados a tornar os intelectuais", em processo de adesão à nova ordem mundial, mais receptivos ao "estilo estadunidense". Para tanto, numerosas fundações filantrópicas foram utilizadas como instituições de fachada e de intermediação financeira, constituindo uma estratégia específica e exitosa de atuação, "para além do território europeu” [...] (NEVES et al., 2010, p. 45) (destaques nossos).

No Brasil, tanto pelo enfraquecimento dos laços democráticos, em função do regime de exceção instaurado pela ditadura pós-64, quanto pela curta e heterônoma experiência de universidade com a qual contávamos, mais expostos e vulneráveis nos encontrávamos no período, a ponto de o american way de fazer ciência não ter sofrido resistências intransponíveis para se impor. A guerra fria, a polarização ou a busca de garantir a gravitação dos países, particularmente os menos desenvolvidos, em torno das duas superpotências dominantes, fazia com que estratégias de força, mas especialmente de coação e cooptação fossem colocadas em ação para garantir o alinhamento. E é neste contexto que gradativamente as reformas vão sendo feitas, visando aparar óbices ou arestas que ainda, porventura, remanesciam, no sentido de instituir uma forma de fazer ciência, com base 
em um pragmatismo utilitário, inclusive nas Ciências Sociais e Humanas, na formatação de pesquisas, controladas administrativamente e na gradativa formação e institucionalização de um novo tipo de intelectual, com duas novas categorias ganhando relevo: tempo e produtividade ou resultados.

Um dos primeiros momentos em que mais visivelmente se insinuam essas novas estratégias foi quando do ressurgimento do Sistema CAPES, na condição de Fundação, após um breve período de extinção, no início dos anos de 1990, no governo Collor de Melo (1990-1992). O estatuto jurídico de fundação passa a propiciar condições de contar com orçamento próprio, aspecto que faculta a possibilidade de induzir ações, processos, com vista a resultados mensuráveis. Abriu-se assim, assumidamente o caminho para vincular a avaliação ao fomento11, amarração que, de um lado, relativiza o próprio conceito de avaliação como processo, em perspectiva educacional, e de outro disponibiliza instrumentos de controle na busca de resultados.

No entanto, sem sombra de dúvidas, o episódio paradigmático e, ao mesmo tempo, divisor de águas de uma inflexão na forma de avaliar os investigadores, com repercussões indeléveis na forma de pesquisar, construir e veicular conhecimentos, bem como de buscar uma relação mais fluida com o mercado, será a avaliação levada a efeito na USP, na gestão de José Goldemberg (1985-1989). De acordo com Paula (2001): "Esse processo de avaliação da "produtividade" docente na USP atingiu seu ápice com a publicação da famosa "lista dos improdutivos" pela Folha de S. Paulo, em fevereiro de 1988, definida pela Coordenadoria de Administração Geral da Reitoria como "relação dos docentes sem produção científica em 1985 e 1986". A partir desses levantamentos, medidas burocrático-racionalizadoras foram tomadas, entre elas a alocação de partes do orçamento das unidades de acordo com a produção dos docentes, desencadeando um processo que estruturou as bases para a exacerbação do produtivismo e da competitividade na USP, mas que gradativamente vai se tornar modelo para o conjunto das universidades.

Paralelamente a isto, no decorrer da década de 1990, o sistema de avaliação da CAPES teve modificado o foco da originária preocupação com a formação de professores para a formação de pesquisadores (KUENZER; MORAES, 2005), propiciando condições de, via avaliação, tornar mais visível o desempenho dos Programas a partir dos índices, 
das repercussões das pesquisas em termos de publicações e de impacto destas, nos rankings nacional e, principalmente, internacionais. A imposição de um modelo de acompanhamento anual dos programas e de avaliação trienal, com aura de legitimação por ser efetivado pelos pares e por contar com a 'arma' do fomento como "espada de Dêmocles", garantirá que da produção se passe a falar em produtividade e esta venha a se metamorfosear em produtivismo, assunto sobre o qual Sguissardi e Silva Junior (2009) se debruçaram e trouxeram elementos que não podem ser desconhecidos ou olvidados.

A avaliação trienal de 1996 a 1998 marcou a história da pós-graduação, em particular a da Educação, pelo descredenciamento de cursos e programas e pelo rebaixamento de outros e ainda pela reclassificação de outros. Enfim, passou-se por aquilo que se convencionou caracterizar como uma "quebra paradigmática" (KUHN, 1978), que marcou uma virada na pós-graduação - a despeito das contestações individuais, dos programas e da própria ANPEd -, que gradativamente veio enquadrando os programas em um modelo indutor, heterônomo, homogêneo, apesar da diversidade intra e entreáreas, permeado pela competitividade e pelo produtivismo, gerando uma intensificação, com profundas repercussões no trabalho/vida dos envolvidos com a pós-graduação.

O circuito vem estreitando-se com a gradativa compatibilização de plataformas, como a do Coleta Capes e a do Lattes, por exemplo, e com a convergência dos processos avaliativos desses órgãos de avaliação e financiamento, bem como com a adesão das Fundações de Amparo à Pesquisa, dos Estados, de outros órgãos e das próprias universidades, de tal forma que a avaliação de um subsidia a avaliação e o fomento dos outros. De um lado, não há dúvidas de que os processos são racionalizados, ganha-se tempo, poupam-se recursos e outras vantagens; de outro, porém, o controle e o direcionamento de processos e produtos leva a que se questione a qualidade do que se faz e se já não seria possível aprender com os processos e os resultados daqueles que nos antecederam nessa caminhada, como pudemos observar anteriormente a respeito da supremacia do american way of doing science.

Enfim, a adesão a esse modelo seria uma das explicações para o apequenamento dos intelectuais e a ínfima repercussão do seu trabalho e 
daquilo que resulta deste em termos de produção e comprometimento, conforme denúncias cada vez mais frequentes a respeito de plágio e da utilização de estratégias, no mínimo questionáveis, por parte de intelectuais engajados, como é ou foi o caso, entre outros, de Wallerstein (2004), Chomsky (2006) e, na Ibero-américa, Tragtenberg (2004) e Sastre (2005). E neste rol não podemos deixar de inserir Pierre Bourdieu (2008) ${ }^{12}$, seja por seu compromisso mais geral com as causas dos excluídos ou dos "despossuídos de capital cultural", seja por seu pioneirismo no esforço de transformar a própria categoria dos intelectuais em 'objeto', melhor dizendo, em "campo" de investigação. O seu empenho em analisar e desvelar as relações abriga-nos naquilo que ele chamou de "campo científico", buscando articulá-lo ou compreendê-lo como campo de poder. Enfim, intelectuais deste calibre são os responsáveis para que a distância entre aqueles que publicam e aqueles que perecem (GIROUX, 2009) seja menos dilatada.

\section{CONCLUSÃO}

As reflexões de Adorno sobre suas experiências científicas nos Estados Unidos assemelham-se a essa ponderação de Bourdieu de não se estabelecer um fosso intransponível entre publicação ou morte intelectual. Tal como foi anteriormente observado, o próprio Adorno reconheceu a relevância do método compreendido como técnica de investigação para que o próprio conhecimento pudesse ser tensionado a ponto de engendrar novas questões e novos significados. Mas, por outro lado, essa mesma produção de conhecimento não poderia ser impulsionada de modo a desenvolver seu potencial crítico, caso permanecesse refém de técnicas de pesquisa aprioristicamente identificadas como imutáveis. Talvez a busca desse equilíbrio, dessa mediania tenha se transformado no principal desafio dos responsáveis pela atual produção acadêmica. De fato, é difícil demarcar as fronteiras entre a publicação de dados de determinada pesquisa, bem como as benesses que a difusão de tal conhecimento possa proporcionar, e a produção açodada de artigos, livros e capítulos de livros, cujos textos tornam-se repetitivos e cada vez mais massificados.

Se a busca de tal equilíbrio, dessa mediania que revitaliza o pensamento aristotélico, presente em seu texto sobre a Ética a Nicômaco 
(ARISTÓTELES, 1991), no contexto ultratecnológico da sociedade atual, é certo que esse esforço não pode limitar-se ao indivíduo que protesta contra o chamado produtivismo acadêmico por meio da publicação de suas críticas em seu blog, ou por saídas individuais que podem ser caracterizadas como quixotescas. Seria oportuno e desejável envidar um esforço coletivo, inclusive com o uso das redes sociais, que seja produto de discussões nos fóruns de encontro tais como a ANPEd, nas iniciativas de criar comissões de avaliação da avaliação da CAPES para que surjam alternativas em relação ao modelo de exaltação do processo de mercantilização dos produtos simbólicos. Uma dessas alternativas poderia ser o engendramento de uma política de avaliação da pós-graduação que estimulasse a valorização da dimensão formativa de mestrandos e doutorados, de modo que os professores que porventura não conseguissem alcançar as metas de produção bibliográfica do triênio CAPES, mas que formassem seus alunos no prazo estipulado pela própria CAPES, pudessem orientar novas dissertações de mestrado e teses de doutorado, ao invés de só voltar a fazê-lo quando atingissem novamente a meta de produção bibliográfica. É justamente esse esforço coletivo, capaz de estimular a reconfiguração identitária dos intelectuais da esfera educacional, que tem a prerrogativa de se opor inclusive àquela personalização, citada anteriormente, dos professores universitários que culpabilizam seus pares como responsáveis por seus desligamentos dos programas de Pós-Graduação. E essa atitude de viés paranoico é espicaçada ao mesmo tempo em que a CAPES parece transformar-se numa espécie de entidade abstrata, de tal modo que se torna mais fácil identificar o coordenador do programa de Pós-Graduação como o único responsável pelos possíveis descredenciamentos daqueles que não atingiram quantitativa e qualitativamente determinado patamar de produção acadêmica. Não é por acaso, portanto, que determinadas patologias, tais como a paranoia e delírios de grandeza, se metamorfoseiam em traços de caráter desejados na e pela atual cultura universitária. Neste contexto, torna-se oportuna a leitura do texto de Trein e Rodrigues (2011) a respeito do "mal-estar na academia e o fetichismo do conhecimento-mercadoria."

Ao comentar a conhecida frase de Adorno de que escrever um poema após Auschwitz é barbárie, Detlev Claussen afirmou que tal 
[...] dito apenas deseja estimular a dolorosa compreensão de uma insolúvel contradição: não se pode escapar da barbárie quem utiliza os meios de comunicação para fazer valer a impressão de que ela não mais existe. Porém, a cultura cessa de existir quando renuncia a uma existência pública [...] (CLAUSSEN, 1995, p. 50).

Assim, se a lógica do produtivismo acadêmico é afeita ao processo de mercantilização de produtos simbólicos, a ponto de arrefecer o potencial crítico de tais escritos numa forma inaudita, por outro lado a renúncia à publicação de artigos, livros e capítulos de livro também produz a aniquilação da própria crítica. É essa contradição que deve ser coletivamente publicizada pelos professores-pesquisadores universitários, os quais atualmente se tornam propagandas de si mesmos quando publicam desmesurada e açodadamente seus trabalhos, sobretudo com o objetivo de que haja novas mediações formativas entre os termos da atual dicotomia dominante do publique ou pereça. Seja qual for a situação, contudo, a saída não está em publicar rotten papers (papéis podres) (DUARTE JUNIOR, 2010), uma vez que o objetivo de produzir e veicular conhecimento foi sobrepujado ou tornou-se a principal justificativa para não perecer. 


\section{REFERÊNCIAS}

ADORNO, T. W. Erz̨iehung zur Mündigkeit. Frankfurt am Main: Suhrkamp Verlag, 1971. ADORNO, T. W. Palavras e sinais: modelos críticos. 2. ed. Petrópolis: Vozes, 1995.

ADORNO, T. W. Minima Moralia: reflexões sobre a vida lesada. São Paulo: Azougue, 2008. ADORNO, T. W. Teoria da semiformação. In: PUCCI, B.; ZUIN, A. A. S.; LASTÓRIA, L. A. C. B. (Orgs.). Teoria crítica e inconformismo: novas perspectivas de pesquisa. Campinas: Autores Associados, 2010.

ADORNO, T. W. HORKHEIMER, Max. Dialética do Esclarecimento: fragmentos filosóficos. Rio de Janeiro: Jorge Zahar Editor,1986.

ADORNO, T. W.; SIMPSON, G. "Sobre música popular”. In: COHN, G. (Org.). Theodor W. Adorno. São Paulo: Ática, 1986. Coleção grandes cientistas sociais.

ARISTÓTELES. Ética a Nicômaco. São Paulo: Abril Cultural, 1991.

BIANCHET'TI, L. Os dilemas do coordenador de programa de pós-graduação. Entre o burocrático-adiministrativo e o acadêmico-pedagógico. In: BIANCHETTTI, L.; SGUISSARDI, V. (Orgs.). Dilemas da pós-graduação: Gestão e avaliação. Campinas: Autores Associados, 2009. BIANCHETTI, L.; MACHADO, A. M. N. Trabalho docente no stricto sensu: publicar ou morrer?! In: FIDALGO, F. S. et al. (Orgs.). A intensificação do trabalho docente: Tecnologias e produtividade. Campinas: Papirus, 2009.

BOURDIEU, P. Homo Academicus. Madrid: Siglo XXI, 2008.

CHAUÍ, M. Intelectual engajado: uma figura em extinção? In: NOVAES, A. (Org.). O silêncio dos intelectuais. São Paulo: Companhia das Letras, 2006.

CHOMSKY, N. A responsabilidade dos intelectuais. In: CHOMSKY, N. O poder americano e os novos mandarins. Rio de Janeiro: Record, 2006.

CLAUSSEN, D. Nach Auschwitz kein Gedicht? In: SCHWEPPENHÄUSER, G.; WISCHKE, M. Impuls und Negativität: Ethik und Ästhetik bei Adorno. Hamburg: Argument Verlag, 1995. p. 44-52.

DEBORD, G. A sociedade do espetáculo. Rio de Janeiro: Contraponto, 1997.

DUARTE JUNIOR, J. F. The rotten papers (ou adiós que yo me voy). In: DUARTE JUNIOR, J. F. A montanha e o videogame: Escritos sobre educação. Campinas: Papirus, 2010. FÁVERO, M. L. A. A reforma universitária de 1968 e a abertura para o ensino superior privado no Brasil. Educação \& Sociedade, Campinas, v. 30, n. 106, p. 15-35, jan./abr. 2009. FÁVERO, O. Reavaliando as avaliações da CAPES. In: ASSOCIAÇÃO NACIONAL DE PÓS-GRADUAÇÃO E PESQUISA EM EDUCAÇÃO - ANPEd. A avaliação da pós-graduação em debate. São Paulo: ANPEd, 1999.

FERNÁNDEZ LIRIA, C.; SERRANO GARCÍA, C. Elplan Bolonia. Madrid: Catarata, 2009. FOLLARI, R. A. La retirada de os intelectuales. Revista Perspectiva, Florianópolis, v. 24, n. 1, p. 341-352, 2006.

GIROUX, H. O ensino superior debaixo de cerco: implicações para os intelectuais. In: PARASKEVA, J. M. (Org.). Capitalismo acadêmico. Mangualde: Edições Pedago, 2009.

JACOBY, R. Os últimos intelectuais: A cultura americana na era da Academia. São Paulo: EDUSP; Trajetória Cultural, 1990.

JACOBY, R. O fim da utopia: Política e cultura na era da apatia. Rio de Janeiro: Record, 2001. 
KUENZER, A.; MORAES, M. C. Temas e tramas na pós-graduação em educação. Educação \& Sociedade, Campinas, v. 26, n. 93, p. 1341-1363, set./dez. 2005. http://dx.doi. org/10.1590/S0101-73302005000400015

KUHN, T. S. A estrutura das revolucões científicas. 2. ed. São Paulo: Perspectiva, 1978.

MORAES, M. C. Recuo da teoria: dilemas da pesquisa em educação. Revista Portuguesa de Educação, Braga, v. 14, n. 1, 2001.

NEVES, L. M. et al. (Orgs.). Direita para o social e esquerda para o capital: Intelectuais da nova pedagogia da hegemonia no Brasil. São Paulo: Xamã, 2010.

PAQUOT, T. $A$ arte da sesta. Porto: Campo das Letras, 1998.

PAULA, M. F. A inserção da universidade na lógica racionalizadora do capital: casos USP e UFRJ. In: SILVA, W. C. (Org.). Universidade e sociedade no Brasil: oposição propositiva ao neoliberalismo na educação superior. Rio de Janeiro: Quartet; Niterói: Intertexto, 2001. p. 15-55. Disponível em: <http://www.anped11.uerj.br/22/PAULA.doc>. Acesso em: 30 jul. 2011.

SASTRE, A. La batalla de los intelectuales: O nuevo discurso de las armas y las letras. Buenos Aires: Clacso Livros, 2005.

SGUISSARDI, V. Universidade, fundação e autoritarismo: O caso da UFSCar. São Carlos: EdUFSCar, 1993.

SGUISSARDI, V.; SILVA JUNIOR, J. R. Trabalho intensificado nas federais: Pós-graduação e produtivismo acadêmico. São Paulo: Xamã, 2009.

STERNBERG, D. How to complete and survive a doctoral dissertation. New York: St. Martin's Press, 1981.

TRAGTENBERG, M. Sobre educação, política e sindicalismo. 3. ed. São Paulo: Editora UNESP, 2004.

TREIN, E.; RODRIGUES, J. O canto de sereia do produtivismo científico: o mal-estar na academia e o fetichismo do conhecimento-mercadoria. Universidade e Sociedade, Brasília, v. 20, n. 47, p. 122-132, fev. 2011.

TÜRCKE, C. Sociedade excitada: filosofia da sensação. Campinas: Editora UNICAMP, 2010. WALLERSTEIN, I. Intelectuais: neutralidade de valores em questão. In: WALLERSTEIN, I. O declinio do poder americano. Rio de Janeiro: Contraponto, 2004.

WATERS, L. Inimigos da esperança: Publicar, perecer e o eclipse da erudição. São Paulo: Editora UNESP, 2006. 


\section{NOTAS}

1 Para mais detalhes sobre a condição e as possibilidades do Coordenador como um "ente sandwichado" em uma estrutura estratificada que começa na CAPES e vem até os pós-graduandos, caracterizada pela pouca margem de manobra, cf. Bianchetti (2009).

${ }^{2}$ Seja na literatura, seja nas pesquisas ou no anedotário, esta é uma questão que aparece frequentemente. Neste útimo aspecto, há pouco circulou pela internet, entre tantas outras formulações em forma de chiste, a que segue: "Artigos passados não movem o Lattes".

${ }^{3}$ Este autor afirma: "A originalidade da obra está diretamente relacionada ao controle do tempo [...]” (1998, p. 32).

4 Ao reportar-se a este aspecto Waters (2006, p. 42), afirma: "As publicações acadêmicas se tornaram tarefas em série, como as peças que rolam pelas esteiras de uma linha de montagem [...]. O produto é tudo o que conta e não sua recepção, não seu uso humano $[\ldots]$ ".. (destaque nosso).

5 No decurso das quais, no Brasil, a pesquisa e a pós-graduação institucionalizam-se e expandem-se, até rapidamente alinharem-se ao modelo hegemônico.

${ }^{6}$ Em página posterior o autor vai fazer referência ao fato de que “[...] este livro é sobre uma lacuna na cultura, a falta de vozes mais jovens, talvez a ausência de uma geração [...] Uma geração intelectual não desapareceu de repente; ela simplesmente nunca apareceu [...]" (1990, p. 16). E mais adiante: "Contudo, os intelectuais mais jovens de esquerda parecem publicamente invisíveis" (p. 18) ou sofreram um eclipse.

${ }^{7}$ Chauí (2006), baseando-se em Marx, afirma que não é apenas o produto da pesquisa que entra no rol dos valores de troca. O próprio intelectual, como uma espécie de 'mercadoria', somente terá atratividade (valor de uso e de troca) se/enquanto for produtivo.

${ }^{8}$ Esta questão dos "recuos" é uma constante nas críticas dirigidas aos pesquisadores, aos intelectuais. Veja-se, por exemplo, entre outros, Moraes (2001) e Follari (2006).

${ }^{9}$ Ao referir-se às produções dos intelectuais acadêmicos de hoje, tão diferentes dos manifestos engajados dos intelectuais públicos que predominaram anteriormente, Jacoby (2001, p. 141) afirma: “[...] os textos acadêmicos de hoje frequentemente invocam para si uma ousadia e uma modernidade inéditas, mas, ao mesmo tempo, deixam quase sempre transparecer deferência e limitação, num emaranhado de clichês e subserviências [...]". O mesmo autor, em outra obra reforça: "A reflexão se retrai quando homenageia amigos e rótulos em lugar de refletir" (1990, p. 13).

${ }^{10} \mathrm{O}$ acordo MEC-USAID é um dos marcos mais vistosos da quebra da até anteriormente dominante posição francófona no Brasil e a expansão da hegemônica condição dos EUA, nas diversas instâncias do país, porém com especial visibilidade e operacionalidade no sistema educacional. É farta a literatura que trata do papel de Rudolf Atcon, assessor norte-americano que vai se transformar em ícone das reformas pelas quais passou a Lei de Diretrizes e Bases, n. 4024/61, particularmente nas mudanças a que foi submetida a 
universidade brasileira em 1968 (Lei 5.540/68) e as do antigo primeiro e segundo graus no início dos anos de 1970 (SGUISSARDI, 1993; FÁVERO, 2009).

11 Anteriormente à década de 1990 a avaliação não repercutia no fomento. Fávero (1999) relata que, no decorrer da década de 1980, uma comissão de avaliação da área de Educação se negou a divulgar os conceitos/avaliações dos programas, por considerar que contribuiriam para a depreciação da área. O interessante é que, apesar da negativa, não houve, por parte da CAPES, represálias para a área, algo impensável atualmente, uma vez que a vinculação avaliação-financiamento fomenta as disputas entre áreas e acabaria fazendo com que parcelas do orçamento fossem realocadas.

12 Está prestes a chegar às livrarias a primeira versão desta obra para o português, pela Editora da UFSC, com tradução de Ione Ribeiro Valle.

Recebido: 17/10/2011

Aprovado: 29/03/2012

Contato:

Centro de Ciências da Educação da UFSC

Campus Universitário

Bairro Trindade

CEP 88010-970

Florianópolis, SC

Brasil 